\title{
Prediction Model for Brake-Drum Temperature of Large Trucks on Consecutive Mountain Downgrade Routes Based on Energy Conservation Law
}

\author{
Menghua Yan and Jinliang Xu $\mathbb{D}$ \\ School of Highway, Chang'an University, Xian 710064, China \\ Correspondence should be addressed to Jinliang Xu; xujinliang@chd.edu.cn
}

Received 7 July 2018; Revised 4 September 2018; Accepted 6 September 2018; Published 30 September 2018

Academic Editor: Rama S. R. Gorla

Copyright (C) 2018 Menghua Yan and Jinliang Xu. This is an open access article distributed under the Creative Commons Attribution License, which permits unrestricted use, distribution, and reproduction in any medium, provided the original work is properly cited.

\begin{abstract}
Excessively high brake temperature may lead to brake fading and failure, resulting in truck runaway down a graded descent. The accurate prediction of the changes in the brake-drum temperature on downgrades can provide theoretical guidance for truck accident countermeasures, such as determining the maximum safe speeds and the locations of truck escape ramps. By analyzing truck accident mechanisms during graded descents and selecting the initial brake-drum temperature, downgrade percentage and length, and the truck weight and speed as independent variables, with the brake-drum temperature as a dependent variable, the downgrade process of a truck can be divided into two stages: speed control at the grade section and emergency braking at the grade end. The energy conversion process in the forms of brake and nonbrake forces in the two stages are analyzed, based on the energy conservation law. A prediction model for the brake-drum temperature of large trucks on consecutive mountain downgrade routes is established, using the heat quantity formula. The model's numerical calculation explicitly demonstrates the effect of all the variables. The brake-drum temperature is positively related to the truck weight, and the percentage and length of the downgrade. The temperature increase in the control speed phase is negatively related to the truck speed, whereas that in the emergency braking phase is positively related. The relationship curves between the variables show that the brake-drum temperature does not change significantly with the truck speed. However, the brake-drum temperatures, under different truck weights, downgrade lengths, and percentages, at the same speed, differ considerably. Compared to the existing empirical fitting model based on specific test data, the proposed model clearly shows the effects of main variables. The proposed model can be used for determining the safe truck speeds and locations of truck escape ramps to provide guidance for drivers and builders.
\end{abstract}

\section{Introduction}

Consecutive mountain-highway downgrade routes are prone to severe truck accidents caused by brake failure towing to high temperature. Therefore, a prediction model for the truck brake temperature on such consecutive downgrade routes is crucial for deploying truck accident countermeasures. In 2016, there were 4,317 fatalities in crashes involving large trucks in the US which was the highest since 2007, and largetruck fatalities increased in that year by $8.6 \%$ compared to 2015, which was higher than the overall increase of 5.6\% in the fatalities [1]. The inspection results of Michigan's Fatal Accident Complaint Team (FACT) indicated that brake problems caused $32.7 \%$ of the truck accidents, establishing as the main cause [2]. Lill's study revealed that among all the investigated accidents, $16 \%$ of the total number (497) and $41 \%$ of runaway downgrade accidents were mainly caused by downshifting failures and defective brakes [3]. Although the number of truck accidents accounted for only $4 \%$ of the total number of motor vehicle accidents in 2016 in the US [1] due to heavy truck weight, large kinetic truck energy, and the large inertia of the truck, the amount of energy requiring dissipation during a truck accident was considerable. Thus, accidents involving trucks were more serious. The gravitational potential energy of a truck translates into kinetic energy during a graded descent.

However, owing to speed limits, driving safety, and traffic flow factors that require the application of brake force to control the truck speed, the kinetic energy is converted into thermal energy by the brake and non-brake forces (rolling 
resistance and aerodynamic drag). The heavier the truck and the steeper the grade, the greater the speed reduced by the truck, generating considerable thermal energy. Part of this thermal energy is dissipated in the external environment, whereas the other is mainly absorbed by the brake drum, increasing its temperature. As the temperature continues to rise, the state of brake fading turns into brake failure, resulting in runaway truck accidents. A study demonstrated that, at a high temperature of approximately $190^{\circ} \mathrm{C}$, the brake drum starts to deform, and the contact surface between the friction plate and brake drum decreases causing brake fading, thereby decreasing the braking capacity. When the temperature increases to $260^{\circ} \mathrm{C}$, the contact surface reduces to the extent that the brake completely fails, causing an outof-control truck [4].

Through the above-mentioned analysis of truck accident mechanisms during graded descents, it can be observed that environmental, road, and vehicle conditions affect the brakedrum temperature. Although the factors are complicated, many studies have been conducted on the temperature increase in truck brake drums, establishing prediction models that provide a theoretical basis for determining truck accident countermeasures, such as the maximum safe speed and the location of truck escape ramps [5].

To assist truck drivers in intuitively selecting the speeds based on the grade severity before entering a consecutive downgrade route, the US has established a series of grade severity rating systems, based on the truck brake temperature. In the early 1960s, Hykes proposed a first-grade severity rating system, based on the US Bureau of Public Road (USBPR) grade categories, which divide all the grades into three categories according to a brake-failure model, based on test data with different grade percentages and lengths [6]. In 1975, Lill revised the Hykes brake-failure model using experimental data and proposed a-second grade severity rating system, based on the work-energy equation [7]. This model considers the effect of representative models on the grade severity. The length of the grade is determined, based on the brake fade position, and the brake drum's excess braking force is determined, based on the braking distance.

However, the above model assumes that the nonbrake force associated with the truck speed is constant. In 1989, the US Department of Transportation and Federal Highway Administration published a user manual on the grade severity rating system (GSRS) [8]. This system establishes a two-stage brake temperature model, based on experimental data during the speed control stage, and the energy conversion law during the emergency stop stage. Subsequently, owing to the development of braking systems, thermodynamics, and engines, a series of studies were conducted to verify the feasibility and effectiveness of the grade severity systems and update them to ensure the accuracy of the prediction temperature and maximum safe speeds [4, 9-11]. Nonetheless, the model is still based on experimental data. The University of Michigan Transportation Research Institute (UMTRI) established a brake-temperature model by examining the internal energy in the brake and the heat transfer from the brake [12].

China established a series of brake-drum-temperature models, based on experimental data measured on specific roads, vehicles, and other conditions [13-15]. The main limitation of these prediction models is that they are empirically fitted to specific test data and may include related problems, such as insufficient samples and experimental losses. Moreover, the models may be unable to clearly depict the effect of various factors concerning the vehicles, roads, and environments. Thus, the user cannot customise the parameters according to the actual conditions, and this limits the application scope of the model.

In the material or friction field, the transient-temperature fields of the brake were analysed by establishing a threedimensional model in combination with numerical analyses, Fourier transform techniques, or finite element methods [16-20]. The limitation of this approach is that only the transient temperature of the brake drum is studied from a mechanical point of view, which may engender the guidelines for further design and improvement of the drum brake rather than the road design or traffic safety. Truck escape ramps are installed as passive arresting systems on dangerous highway declines to stop runaway trucks on steep slopes as a means of promoting highway safety. It is crucial to determine the specific location of a truck escape ramp setup. Studies have shown that the location of such ramps is guided primarily by economics, weather conditions, topography, roadway alignment, accident location, degree of slope, and the maximum potential speed of runaway trucks [21]. These ramps can only be used for roads that have been in operation for a considerable period. In addition, this method operates at the expense of life and property. However, the introduction of a prediction model for the brake-drum temperature can forecast the brake failure position and provide guidance for the specific locations of truck escape ramps, during the road design stage.

To address the limitations of the above approaches, this research intends to establish a brake-drum prediction model on a more theoretical basis. According to the above analysis, the source of the brake-drum temperature is the friction in the plate/drum interface. Therefore, the most direct method for predicting the brake-drum temperature is by multiplying the brake force by the relative displacement. However, these two factors are variable and difficult to determine.

On the contrary, the gravity, rolling resistance, and aerodynamic drag of trucks are relatively easy to determine. According to the energy conservation law, the total energy of the truck system remains unchanged, despite the energy conversion during a graded descent. To predict the brakedrum temperature, the energy transferred to the brake drum must be determined. According to the energy forms involved, the downgrade process of the truck can be divided into two stages: speed control at the grade section and emergency braking at the end of the grade. Accordingly, we calculate the energy transferred to the brake drum in these two stages based on the energy conversion law and then establish the brake-drum temperature prediction model, using the heat quantity formula. This study intends to establish a prediction model for the brake-drum temperature, with a full theoretical foundation and extensive application scope to clearly demonstrate the effect of the main parameters, including the ambient temperature, initial brake-drum temperature, truck weight 
and speed, and grade percentage and length, while enabling the user to customize the parameters according to the actual conditions.

The approach presented here is based on the energy conservation law and aims to establish a temperature prediction model suitable for the brake drums of trucks on consecutive mountain downgrade routes, using a theoretical derivation method. Compared with the existing empirical fitting model, based on specific test data, the proposed model is based on a full theoretical foundation, namely, the energy conservation law; it addresses the lacuna in the empirical formula by clearly depicting the effect of the main variables on the brake-drum temperature. The proposed model can be used to determine the safe truck speeds and locations of the truck escape ramps by permitting users to input parameters according to the actual situation.

The remainder of this paper is organised as follows. Section 2 describes the energy conversion process of a downgrade truck, the energy distributed to each brake, and the downgrade truck braking model. Section 2 introduces the modelling process, the assumptions, and the theoretical basis. Section 3 presents the results of this research, including the relationship curves between the main parameters and the brake temperature, thereby demonstrating the effect of each factor on the brake temperature. Section 4 provides the conclusions, discussions, and suggestions for further research.

\section{Mathematical Model}

The drum brake system mainly includes two parts: the brake drum and friction plate (Figure 1). When the braking process occurs, hydraulic pressure is forced upon the piston. The friction plate and brake drum are, therefore, in relative sliding contact. The nonrotating friction plate applies a frictional torque on the rotating brake drum to resist movement as the truck slows, remaining at the same velocity during the consecutive mountain downgrade routes, and eventually stopping. However, as a side effect, the friction at the plate/drum interface generates heat. A portion of the heat increases the brake temperature, whereas the other portions are dissipated to the ambient by convection and radiation heat transfer. Continuous heating of the brake drum causes the condition to progress from brake fading to failure, resulting in a runaway truck.

The two sources for the temperature increment in the brake drum are the energy due to speed control and emergency stop. The most unfavourable situation is speed control for the entire grade combined with an emergency stop at the end of the grade. If the truck can stop at the end of the grade, where the heat generated by speed control at that grade is the maximum, the truck can also stop further up the grade. The brake-drum temperature in the speed control stage can be used as an input parameter for the emergency stop stage. In general, a truck has sufficient braking capacity to ensure a constant descent speed, but not for slowing down or stopping in adequate time to respond to emergencies. This is because the extra energy generated by emergency braking increases the temperature of the brake drum to the temperature limit,

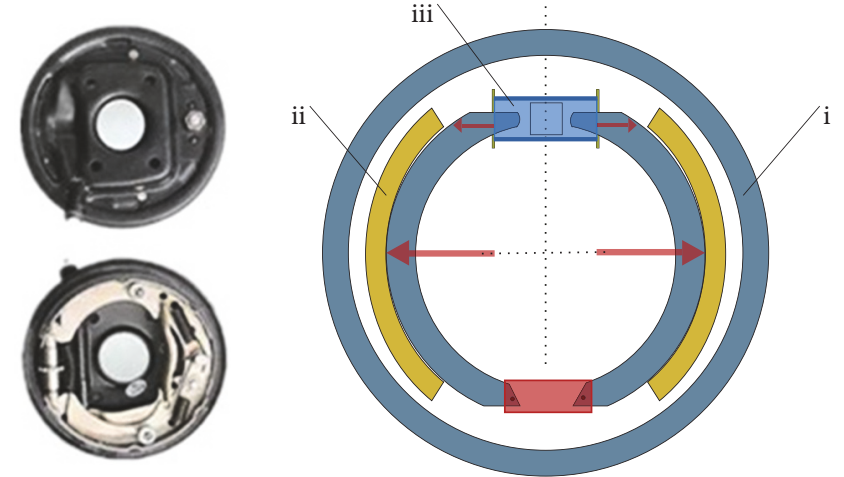

FIGURE 1: Plate-drum assembly with forces applied to the drum: (i) brake drum, (ii) friction plate, and (iii) piston.

resulting in brake fading and failure, when braking is urgently needed [8].

For the proposed temperature model, the following are assumed:

(1) The truck is in a speed-controlled state without tractive force during a graded descent. It is equipped with an antilock braking system and has no brake assistance system.

(2) The material properties are isotropic and independent on the temperature. The main part of the brake drum that participates in heat production is a regular cylinder. The brake drum is evenly heated and there is no temperature gradient along the wall thickness.

(3) All the frictional heat is absorbed by the brake drum. The effect of the other parts of the brake chamber in the process of heat generation and dissipation are ignored.

(4) The wear at the plate/drum interface is negligible.

(5) The braking force is evenly distributed to the brakes, ignoring the effect of the road and cargo loading conditions.

Energy exchange occurs between the truck and ambient due to the effect of the nonbraking force. From Figure 2, it can be observed that, during operation, the nonbrake force on the truck mainly includes the gravity, rolling resistance, and aerodynamic drag, which change the internal energy of the truck. The sum of the rolling resistance and aerodynamic drag slowing the truck motion on a downgrade is referred to as the total drag force.

The positive work of gravity converts the gravitational potential energy into the kinetic energy of the truck, during grade descent. The kinetic energy is controlled by the brake operation, while the friction at the plate/drum interface simultaneously generates heat. As the temperature of the brake drum increases, it continuously dissipates heat to the ambient. In addition, the rolling resistance and aerodynamic drag of the driving truck produce negative power in generating heat. In the emergency braking process of the truck, the time and distance are both considerably less; it is assumed that the gravity, rolling resistance, and aerodynamic drag do not play a role; only the friction at the plate/drum interface contributes in converting the kinetic energy into the internal energy of the brake drum. 


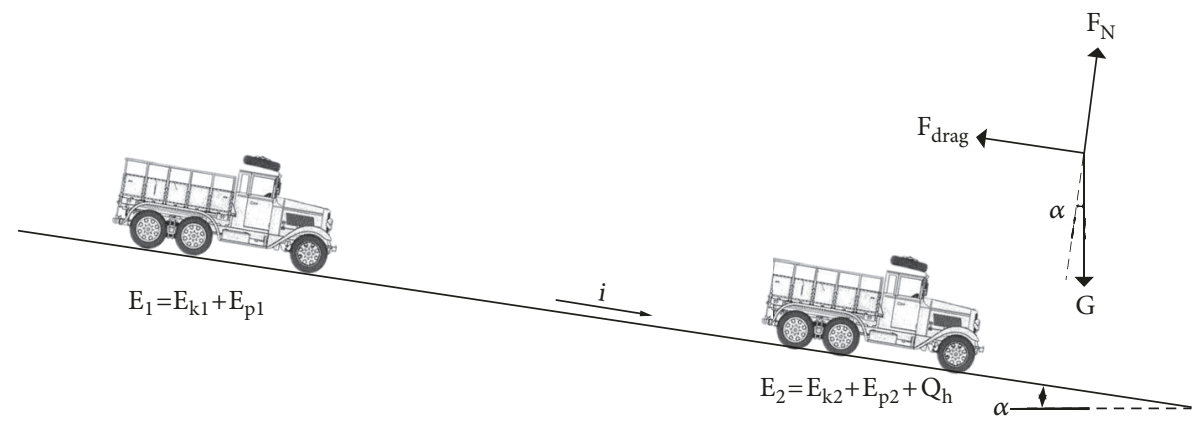

FIGURE 2: Energy and free body diagram of a truck on a downward grade.

\subsection{Brake-Drum Temperature Prediction Model during the Speed Control Stage}

2.1.1. Energy Conversion Process. Figure 2 shows the energy of the truck on consecutive downgrade routes. On top of the grade, the kinetic and gravitational potential energies of the truck are $E_{k 1}$ and $E_{p 1}$, respectively. On a downgrade route, the conversion of the gravitational potential energy into kinetic energy causes the truck speed to increase, owing to the effect of gravity. Thus, the driver is required to frequently and continuously brake for controlling the truck speed to an approximate speed limit by converting the kinetic energy into the brake-drum thermal energy. Meanwhile, a portion of the energy of the truck dissipates through the effect of the rolling resistance and aerodynamic drag during the driving process. At the end of the grade, before emergency braking, the truck's kinetic energy fluctuates, the gravitational potential energy decreases, and the thermal energy, $Q_{h}$, is added.

According to the energy conservation law, the gross energy of a truck on a downgrade road remains constant, regardless of the changes in the various energies, as shown in (1).

$$
\begin{aligned}
& E_{1}=E_{2} . \\
& E_{1}=E_{k 1}+E_{p 1} . \\
& E_{2}=E_{k 2}+E_{p 2}+Q_{h} .
\end{aligned}
$$

Therefore, (1), (2), and (3) can be converted to (4), as follows:

$$
\begin{aligned}
Q_{h} & =\left(E_{k 1}-E_{k 2}\right)+\left(E_{p 1}-E_{p 2}\right) \\
& =\frac{1}{2} m\left(v_{1}^{2}-v_{2}^{2}\right)+m g i s
\end{aligned}
$$

Equation (4) calculates the total heat generated by the brake and nonbrake forces, during a graded descent. It shows that although the vehicle speed constantly fluctuates around the speed limit during a graded descent, the total heat is only related to the speed at the top and end of the grade and does not involve the changing speeds further up the grade.

By applying the model, truck-related parameters, such as the weight, size, and speed, can be determined for a representative vehicle, according to the traffic investigation. Additionally, road-related parameters, such as the grade percentage and length, can be determined, according to the actual design parameters of the road.

2.1.2. Effect of the Nonbrake Force. From the above analysis, it can be observed that the truck is required to overcome the effect of the rolling resistance and aerodynamic drag during a graded descent. The existence of these two forces is favourable for the temperature of the brake drum, but not for fuel economy. The energy form is converted by the work done by the force; hence, the internal energy converted into the brake-drum thermal energy can be determined by calculating the work of the nonbrake force.

(1) Heat Generated by the Rolling Resistance. When the truck tires are in rolling contact with rigid roads, there is minimal hysteresis loss due to the internal friction of the tire, which mainly involves a recoverable elastic deformation. In this paper, it is assumed that the tire is a rigid body, ignoring the effect of the hysteresis loss and considering only the effect of the rolling resistance. The rolling resistance is related to the tire type, road-surface condition, and travel speed and can be approximated as follows:

$$
F_{r}=0.001 \times m \times\left(C_{1}+C_{2} v\right),
$$

where $C_{1}$ and $C_{2}$ are parameters related to the tire types. For a radial tire, $C_{1}=6$ and $C_{2}=0.068$; for mixed tires, $C_{1}=5.3$ and $\mathrm{C}_{2}=0.044$.

For downgrade roads, as the slope, $i$, is very small, it is approximately assumed that the relative displacement of the tires on the road is equal to the length of the grade, $s$. Therefore, the heat generated by friction at the tire/pavement interface is as follows:

$$
Q_{r}=F_{r} \times s
$$

(2) Heat Generated by the Aerodynamic Drag. The truck is subjected to aerodynamic drag in the direction of travel, while driving. In general, it is considered that aerodynamic drag is a complete resistance and acts on the wind centre. In the driving range of the truck, the value of the aerodynamic drag is proportional to the dynamic pressure of the relative airflow velocity, as follows:

$$
F_{a}=\frac{1}{2} C_{D} A \rho u_{r}^{2}
$$


Similarly, the relative displacement of the tires and road is equal to the length of the grade, $s$. The heat generated by aerodynamic drag is given by

$$
Q_{a}=F_{a} \times s .
$$

According to (5) and (7), it is evident that the truck speed influences the value of the nonbrake force, in which the rolling resistance is proportional to the truck speed, and the aerodynamic drag is proportional to the square of the truck speed. In turn, the rolling resistance and aerodynamic drag affect the speed of the truck, and the effect is accumulated under the influence of the grade length.

From the above, it can be determined that the truck speed fluctuates constantly around the speed limit, during a graded descent. Thus, it is difficult to unify the speed. There are generally two approximate approaches for obtaining the vehicle speed: $85 \%$ of the speed and the average speed. Considering the safety of most vehicles, the truck speed is taken as the operating speed, $v_{85}$. After calculation, for a 50-t truck with a speed difference of $5 \mathrm{~km} / \mathrm{h}$, the rolling resistance difference is approximately $5 \mathrm{~N}$, and the aerodynamic drag difference is approximately $175 \mathrm{~N}$. Therefore, the difference between the calculated and actual speeds has minimal influence on the rolling resistance; however, it has a greater impact on the aerodynamic drag. The impact is accumulated by the effect of the grade length.

2.1.3. Heat Transfer between the Brake Drum and the Ambient. A portion of the internal energy absorbed by the brakes increases the brake temperature, whereas the other portion is dissipated by convection and radiation to the ambient, in accordance with heat transfer. There are three basic thermal-energy transfer modes: thermal conduction, thermal convection, and thermal radiation. It can be observed from the above assumptions that there is no thermal conduction between the brake drum and the ambient, only thermal convection and radiation. Thus, it is a comprehensive heat transfer problem.

(1) Convection Heat Transfer. Thermal convection refers to the relative displacement between fluid parts due to the macroscopic motion of fluids, and the heat transfer caused by the intermixing of cold and hot fluids. To facilitate the cooling of the brake drum, its external surface is generally in full contact with air. When air flows over it, a natural convection heat transfer process occurs between the fluid and external surface of the brake drum. The equation for convective heat transfer, in accordance with Newton's law of cooling, is as follows:

$$
\begin{aligned}
& \Phi_{c}=A^{\prime} h_{c}\left(t_{w}-t_{f}\right), \\
& h_{c}=0.92+a v \times \exp \left(-\frac{v}{328}\right),
\end{aligned}
$$

where $a$ is an empirical formula coefficient, which is 0.7 for the front wheel brakes and 0.3 for the rear wheel ones $\left(\mathrm{W} /\left(\mathrm{m} \cdot{ }^{\circ} \mathrm{C}\right)\right)$.

For a truck with a speed of $50 \mathrm{~km} / \mathrm{h}$, temperature of $200^{\circ} \mathrm{C}$, and external surface area of $0.45 \mathrm{~m}^{2}$, convection heat transfer between the front-wheel brake and environment at $25^{\circ} \mathrm{C}$ is approximately $0.8 \mathrm{~kJ} / \mathrm{s}$, and that at the rear-wheel brake is approximately $0.38 \mathrm{~kJ} / \mathrm{s}$.

The external surface area of the brake drum is approximated based on the actual outer diameter and height of the simplified physical model of the brake drum. Owing to the different truck paths reaching the top of the grade, the initial external surface temperature of the brake drum is difficult to unify; however, the temperature of the brake drum is generally around $50-60^{\circ} \mathrm{C}$, when the truck operates on general roads. Therefore, in this paper, the initial temperature of the truck is assumed to be $50^{\circ} \mathrm{C}$. The fluid outside the brake drum should be at ambient temperature.

(2) Radiant Heat Transfer. The transfers of energy by an object through electromagnetic waves is called thermal radiation. A truck is required to brake frequently, while driving at constant speed on downgrade routes, raising the temperature of the brake drum. Therefore, the brake drum radiates heat to the ambient. Because the radiance is difficult to determine, in this paper the ratio of the radiant power of the brake drum to that of a black body at the same temperature is introduced, in accordance with the Stefan-Boltzmann law. The radiant heat transfer equation of the brake drum is as follows:

$$
\Phi_{r}=A^{\prime} \varepsilon C_{0}\left[T_{1}^{4}-T_{2}^{4}\right]
$$

where $\varepsilon$ is emissivity of the brake drum, indicating the ratio of the radiant power of the brake drum to that of a black body at the same temperature. It is related to the type and surface condition of the object, which is generally determined by experiments. The material of the brake drum is mostly cast iron, and the blackness is $0.64-0.78$, when the temperature is $200-600^{\circ} \mathrm{C} . \mathrm{C}_{0}$ is the radiance of the black body, which is a natural constant, whose value is $5.67 \times 10^{-8} \mathrm{~W} /\left(\mathrm{m}^{2} \cdot \mathrm{K}^{4}\right) . T_{1}$ is the thermodynamic temperature of the black body, which is equal to the temperature of the brake drum, $t_{w}(\mathrm{~K}) . T_{2}$ is the ambient temperature $(\mathrm{K})$.

For a truck with a speed of $50 \mathrm{~km} / \mathrm{h}$, temperature of $200^{\circ} \mathrm{C}$, external surface area of $0.45 \mathrm{~m}^{2}$, and external environment of $25^{\circ} \mathrm{C}$, the radiation heat transfer amount is approximately $0.7 \mathrm{~kJ} / \mathrm{s}$.

The heat exchanged between a heat conduction object and fluid can be integrated by the instantaneous heat flux over time:

$$
\begin{aligned}
Q_{\mathrm{d}} & =\int_{0}^{t} A^{\prime}\left[h_{c}\left(t_{w}-t_{f}\right)+\varepsilon C_{0}\left(\frac{t_{w}}{100}\right)^{4}\right] d t \\
& =\sum_{j=1}^{n} A^{\prime}\left[h_{c}\left(t_{w j}-t_{f}\right)+\varepsilon C_{0}\left(\frac{t_{w j}}{100}\right)^{4}\right] .
\end{aligned}
$$

As the heat transfer between the brake and ambient is related to the temperature of the brake drum and the brake temperature changes as the truck travels downgrade, an approximate calculation of the total heat dissipation can be performed according to the Riemann integral, whose core idea is to determine the integral value through infinite 
approximation; the calculation interval adopted in this paper is 1-s for the truck. To obtain the changed brake-drum temperature within each calculation interval, $t_{w j}$, the final brakedrum temperature also needs to be iteratively calculated at 1-s intervals. The brake-drum temperature of the previous second is used as the input parameter for the next-second calculation.

In summary, the first portion of the heat that increases the temperature of the brake drum is calculated as follows:

$$
Q_{1}^{\prime}=Q_{h}-Q_{r}-Q_{a}-Q_{d}
$$

2.1.4. Energy Distribution among Brake Drums Belonging to the Same Truck. The heat originally absorbed by the brakes must be distributed to the different brake drums of a truck in accordance with the braking force distribution coefficient, as shown in (14) and (15). Although a truck generally has a fixed ratio braking force distribution system, the actual and ideal braking force distribution curves differ significantly, and the braking efficiency is low. Modern cars are equipped with braking force adjustment devices, which can change the braking force distribution according to factors, such as the braking intensity and load, such that it can approach the ideal braking force distribution curve. The actual braking conditions change the ideal braking curve. Therefore, it is difficult to determine the distribution coefficient of the braking force. Hence, in this study, it is assumed that braking force is equally distributed to each brake, as shown in (16).

For the front axles,

$$
Q_{F}=\frac{\beta}{2 n_{1}} \times Q_{1}^{\prime},
$$

and for the rear axles,

$$
Q_{R}=\frac{1-\beta}{2 n_{2}} \times Q_{1}^{\prime},
$$

where $\beta$ is the braking force distribution coefficient, which is equal to the ratio of the front axle braking force to the vehicle braking force.

$$
Q_{1}=\frac{Q_{1}^{\prime}}{2 n} .
$$

2.1.5. Prediction Model during the Speed Control Stage. In summary, the predicted temperature of the brake drum during the speed control stage is equal to the sum of the initial temperature and the increased temperature in the speed control stage. The increase in temperature is calculated according to the internal energy converted into the brake drum thermal energy and the heat dissipated from the brake drum to the environment, based on the heat quantity formula, (17).

$$
Q=m c \Delta t
$$

$$
\begin{aligned}
T_{f 1} & =T_{0}+\frac{Q_{1}}{m^{\prime} C}=T_{0}+\frac{1}{2 n m^{\prime} C}\{m g i s \\
& -0.001 m\left(C_{1}+C_{2} v_{85}\right) s-\frac{1}{2} C_{D} A \rho v_{85}{ }^{2} s \\
& \left.-\sum_{i=0}^{n} A^{\prime}\left[h_{c}\left(t_{w}-t_{f}\right)+\varepsilon C_{0}\left(T_{1}^{4}-T_{2}^{4}\right)\right]\right\} .
\end{aligned}
$$

2.2. Brake-Drum Temperature Prediction Model in the Emergency Braking Stage. Equation (2) indicates that the longer the grade, the greater the percentage of the grade and the higher the temperature of the brake drum. Therefore, considering the most unfavourable situations, as long as the brake capacity of the truck can ensure an emergency stop at the end of the grade, it can ensure an emergency stop further up the grade. The emergency stop process is very brief, for example, the time required to reduce the truck speed from $30 \mathrm{~km} / \mathrm{h}$ to 0 with a deceleration of $5 \mathrm{~m} / \mathrm{s}^{2}$ is only $1.67 \mathrm{~s}$, along with a brake activation time of $0.2-0.9 \mathrm{~s}$ and a driver reaction time of $0.3-1.0 \mathrm{~s}$. Thus, the distance travelled by the truck in this process is approximately $11-22 \mathrm{~m}$. Hence, the effect of the nonbrake forces is neglected in this process, and the energy absorbed by the brakes is equal to the change in the kinetic energy of the truck. Therefore, the second portion of the heat that increases the temperature of the brake drum is calculated as follows:

$$
Q_{2}=E_{k 1}=\frac{1}{2} m v_{2}^{2}
$$

According to the heat quantity formula, the increase in temperature in the emergency braking stage is calculated as follows:

$$
T_{f 2}=\frac{Q_{2}}{2 n m^{\prime} C}=\frac{1}{2 n m^{\prime} C} \times \frac{1}{2} m v_{2}^{2} .
$$

Equation (19) shows that the thermal energy generated during emergency stop is only related to the truck weight and speed. Because the magnitude of the truck weight is $10^{4}$, slight changes in the truck speed will have a significant impact on $Q_{2}$. However, due to the cumulative effect of the length of the grade, the speed control stage may have a greater influence on the brake-drum temperature than the emergency stop stage. Equation (13) indicates that a 30 -t truck traveling at $50 \mathrm{~km} / \mathrm{h}$ would experience a brake temperature of $7.4^{\circ} \mathrm{C}$, on braking to a sudden stop.

2.3. Brake-Drum Temperature Prediction Model. In summary, the predicted temperature of the brake drum is equal to the sum of the initial temperature and the increased temperature of the speed control and emergency stop stages. The increase in temperature is calculated as the internal energy converted into the brake-drum thermal energy, and the heat dissipates from the brake drum to the environment, based on the heat quantity formula. 


$$
\begin{aligned}
T_{f} & =T_{f 1}+T_{f 2}=T_{0}+\frac{1}{2 n m^{\prime} C}\left\{m g i s+\frac{1}{2} m v_{85}^{2}\right. \\
& -0.001 m\left(C_{1}+C_{2} v_{85}\right) s-\frac{1}{2} C_{D} A \rho v_{85}{ }^{2} s \\
& \left.-\sum_{i=0}^{n} A^{\prime}\left[h_{c}\left(t_{w}-t_{f}\right)+\varepsilon C_{0}\left(T_{1}^{4}-T_{2}^{4}\right)\right]\right\} . \\
T_{f} & =f\left(v_{85}, m, i, s\right) .
\end{aligned}
$$

Equation (21) clearly shows the effect of the initial brake temperature, speed, and weight of the truck, and the percentage and length of the grade. The model permits the user to input the relevant parameters based on actual conditions.

In the model, the weight of the brake drum is the actual weight of the brake drum in a representative vehicle. The effective heat capacity of the brake drum can be determined, according to the brake drum material, which is grey cast iron, HT250.

\section{Results}

As shown in (22), the impact factors of the truck downgrade braking model mainly include the speed $v_{85}$, gross truck weight $m$, percentage of the grade $i$, and length of the grade $s$. However, there is a correlation among the three factors, $\Delta h, i$, and $s$, as follows.

$$
\Delta h=i \times s .
$$

The height difference can be calculated by the percentage and length of the grade. Therefore, this paper mainly analyses the effect of the four variables, namely, the speed and weight of the truck, and the percentage and length of the grade, on the brake drum temperature.

To demonstrate the validity of the model, as an example, the parameter values as listed in Table 1 were used, based on the actual road, truck, and environmental conditions.

The analysis of (20) shows that brake-drum temperature is positively correlated with the truck weight and the percentage and length of the downgrade. The brakedrum temperature increment in the first phase is negatively correlated with the truck speed, whereas, in the second phase, it is positively correlated. The proposed model can be used to determine the locations of the truck escape ramps and the safe truck speeds, under different truck weights. Therefore, the relationship between the length of the downgrade and the brake-drum temperature increment in the speed control phase, under different combinations of the other variables, is shown in Figure 3. The relationships between the truck weight, speed, and brake-drum temperature increment in the speed control and emergency braking phases, under different combinations of the other variables, are depicted in Figures 4 and 5.

Figure 3 demonstrates that, under each combination of the truck speed and weight, the brake-drum temperature increment in the speed control phase increases significantly with the increase in the length as well as percentage of the

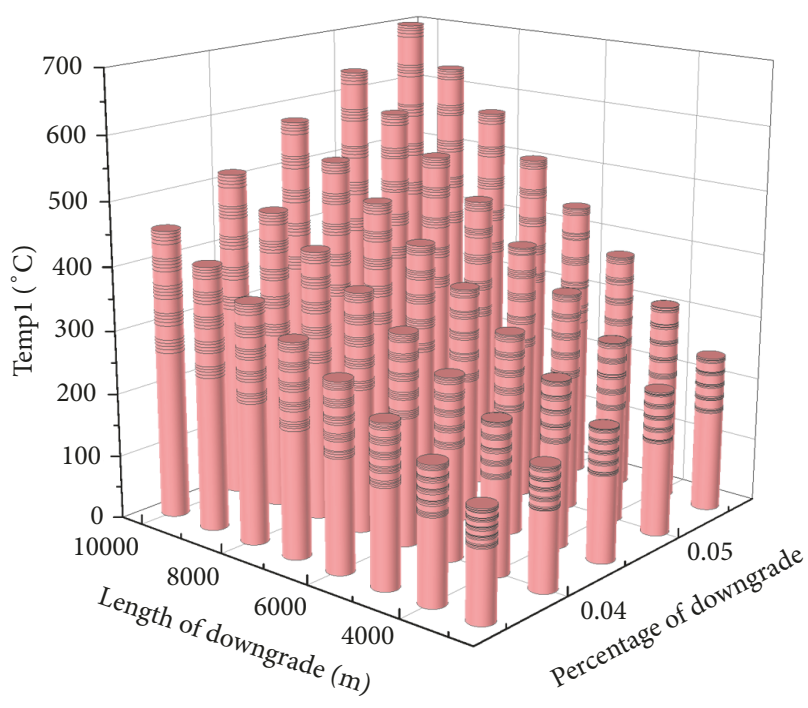

FIgURE 3: Relationship between the length and percentage of the downgrade and temp $p_{1}$.

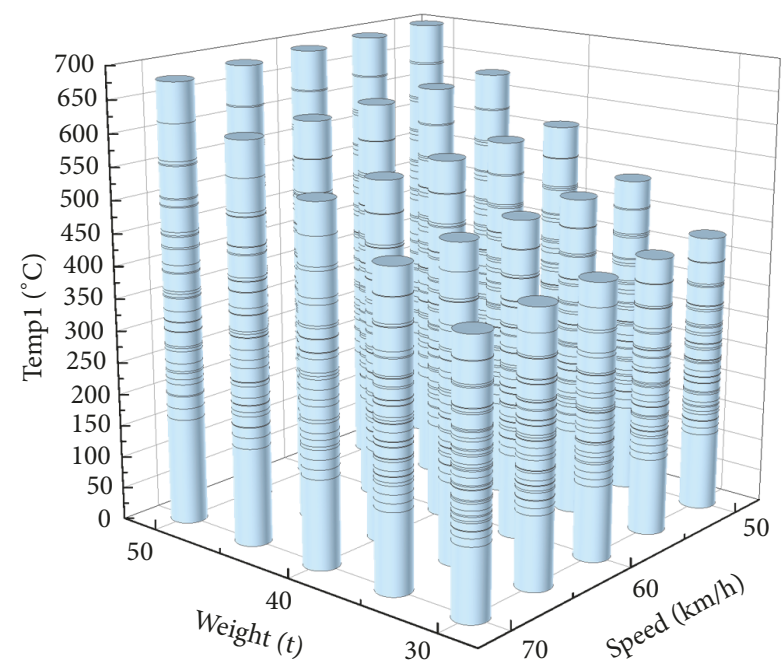

FIGURE 4: Relationship between the truck weight, speed, and temp $\mathrm{p}_{1}$.

downgrade. For example, for a combination of $70-\mathrm{km} / \mathrm{h}$ truck speed, 50-t truck weight, and 3.5\% downgrade percentage, the brake-drum temperature increases from $150^{\circ} \mathrm{C}$ to $460^{\circ} \mathrm{C}$, as the length of the downgrade increases from $3 \mathrm{~km}$ to $10 \mathrm{~km}$. Meanwhile, under the same conditions, the temperature increases from $255^{\circ} \mathrm{C}$ to $690^{\circ} \mathrm{C}$ for a downgrade percentage of $5.5 \%$.

Figure 4 indicates that, for each combination of downgrade length and percentage, the brake-drum-temperature increment in the speed control phase increases significantly with the increase in the truck weight and increases slightly with the change in truck speed. For example, for a combination of $10-\mathrm{km}$ downgrade length, 5.5\% downgrade percentage, and $70-\mathrm{km} / \mathrm{h}$ truck speed, the brake-drum temperature increases from $350^{\circ} \mathrm{C}$ to $675^{\circ} \mathrm{C}$ as the truck weight increases from $30 \mathrm{t}$ to $50 \mathrm{t}$. Meanwhile, under the same conditions, the 
TABLE 1: Parameter values.

\begin{tabular}{|c|c|c|c|}
\hline Parameter name & Symbol & Unit & Value \\
\hline Number of axles & $n$ & 1 & 6 \\
\hline Weight of brake drum & $m^{\prime}$ & $\mathrm{kg}$ & 60 \\
\hline Heat capacity of brake drum & C & $\mathrm{J} /\left(\mathrm{kg} \cdot{ }^{\circ} \mathrm{C}\right)$ & 545 \\
\hline Gross truck weight & $m$ & $\mathrm{t}$ & $30,35,40,45,50$ \\
\hline Gravitational acceleration & $g$ & $\mathrm{~m} / \mathrm{s}^{2}$ & 9.8 \\
\hline Height difference & $\Delta h$ & $\mathrm{~m}$ & $200,300,400,500,600$ \\
\hline Slope & $i$ & 1 & $0.035,0.04,0.045,0.05,0.055$ \\
\hline Speed & $v_{85}$ & $\mathrm{~km} / \mathrm{h}$ & $50,55,60,65,70$ \\
\hline Coefficient & $C_{1}$ & 1 & 6 \\
\hline Coefficient & $C_{2}$ & 1 & 0.068 \\
\hline Slope length & $s$ & $\mathrm{~km}$ & $3,4,5,6,7,8,9,10$ \\
\hline Drag coefficient & $C_{D}$ & 1 & 0.8 \\
\hline Windward area of the truck & $A$ & $\mathrm{~m}^{2}$ & 8.75 \\
\hline Air density & $\rho$ & $\mathrm{N} \cdot \mathrm{s}^{2} \cdot \mathrm{m}^{-4}$ & 1.2258 \\
\hline External surface of the brake drum & $A^{\prime}$ & $\mathrm{m}^{2}$ & 0.45 \\
\hline Initial temperature of the brake drum & $T_{0}$ & ${ }^{\circ} \mathrm{C}$ & 50 \\
\hline Environmental temperature & $t_{f}$ & ${ }^{\circ} \mathrm{C}$ & 25 \\
\hline Emissivity of the brake drum & $\varepsilon$ & 1 & 0.65 \\
\hline Radiance of the black body & $C_{0}$ & $\mathrm{~W} /\left(\mathrm{m}^{2} \cdot \mathrm{K}^{4}\right)$ & $5.67 \times 10^{-8}$ \\
\hline
\end{tabular}

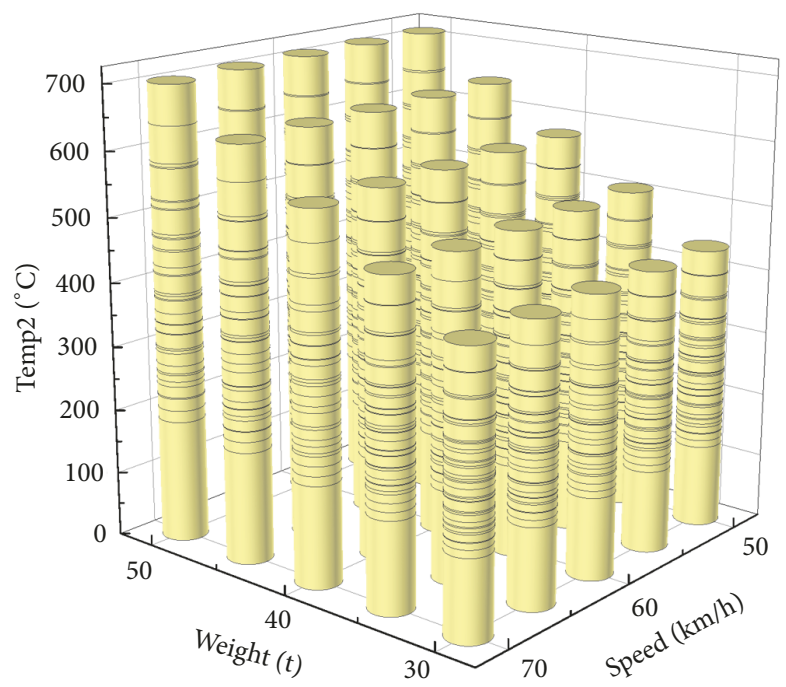

FIGURE 5: Relationship between the truck weight, speed, and temp $\mathrm{P}_{2}$.

temperature increases from $375^{\circ} \mathrm{C}$ to $690^{\circ} \mathrm{C}$ for a truck speed of $50 \mathrm{~km} / \mathrm{h}$.

Figure 5 demonstrates that the brake-drum temperature increment in the emergency braking phase is slight, and emergency braking has negligible effect on the brake-drum temperature.

Comparing Figures 4 and 5, under the same conditions, the brake-drum temperature difference between the speed control and the emergency braking phases is less than $50^{\circ} \mathrm{C}$. In Figure 4, the brake-drum temperature decreases as the truck speed increases, while, in Figure 5, the brake-drum temperature does not change substantially with the truck speed. This is because the brake-drum temperature in the speed control phase is negatively correlated with the truck speed, whereas in the emergency braking phase it is positively correlated.

\section{Discussion and Conclusion}

In this paper, a prediction model was proposed for the brakedrum temperature of large trucks on consecutive mountain downgrade routes. Considering the most unfavourable situation, the analysis is divided into two phases: the speed control and emergency braking stages, as per the operating state of the truck, and the respective models of the two stages were built, based on the energy conservation law. Through numerical calculation and the Origin software drawing, the influence of the main parameters (truck weight and speed, downgrade length, and percentage) on the brakedrum temperature was studied.

From the obtained results, we can conclude that the brake-drum temperature continues to increase on consecutive mountain downgrade routes, and the temperature increase is closely related to the percentage and length of the downgrade. In addition, we can conclude that, under the same driving conditions, the brake-drum temperatures of trucks with different weights vary considerably. The obtained results are highly beneficial for determining the recommended descent speeds for various classes of truck weights and the locations of truck escape ramps.

The results obtained, in general, are satisfactory in comparison with the previous research. Further, an experimental study of the brake drum can be undertaken to determine the agreement between the model and a real device.

However, some points, for example, the neglected effect of the mechanical crash loss of the truck on the brake temperature and the radial temperature gradient of the brake 
drum, remain to be studied further. Hence, in future, we intend to focus on multiple braking models and the automatic driving of trucks on consecutive mountain downgrade routes.

\section{Nomenclature}

$E_{1}$ : Gross energy of the truck on top of the grade, J

$E_{k 1}$ : Kinetic energy of the truck on top of the grade, J

$E_{p 1}$ : Gravitational energy of the truck on top of the grade, $J$

$i$ : $\quad$ Percentage of the grade, $\%$

$E_{2}$ : Gross energy of the truck at the end of the grade, J

$E_{k 2}$ : Kinetic energy of the truck at the end of the grade, $\mathrm{J}$

$E_{p 2}$ : Gravitational energy of the truck at the end of the grade, J

$Q_{h}$ : Thermal energy generated, while driving from the top to the end of the grade, J

$F_{\text {drag }}$ : Sum of the rolling resistance and aerodynamic drag, $\mathrm{N}$

$F_{N}:$ Road support, $\mathrm{N}$

$\alpha$ : $\quad$ Angle between the road surface and horizontal plane, ${ }^{\circ}$

G: Truck gravity, N

$m$ : Gross truck weight, $\mathrm{kg}$

$v_{1}$ : Truck speed on top of the grade, $\mathrm{m} / \mathrm{s}$

$v_{2}$ : Truck speed at the end of the grade, $\mathrm{m} / \mathrm{s}$

$g$ : Gravitational acceleration, $\mathrm{m} / \mathrm{s}^{2}$

$s$ : $\quad$ Length of the grade, $\mathrm{m}$

$F_{r}$ : Rolling resistance, $\mathrm{N}$

$C_{1}$ : $\quad$ Parameter related to the tire types

$\mathrm{C}_{2}$ : $\quad$ Parameter related to the tire types

$v_{85}$ : Truck operating speed, $\mathrm{m} / \mathrm{s}$

$Q_{r}$ : Heat generated by the rolling resistance, J

$F_{a}: \quad$ Aerodynamic drag, $\mathrm{N}$

$C_{D}$ : Drag coefficient

A: $\quad$ Windward area, $\mathrm{m}^{2}$

$\rho: \quad$ Air density, $\mathrm{kg} / \mathrm{m}^{3}$

$u_{r}$ : Relative speed of air and the truck, $\mathrm{m} / \mathrm{s}$

$Q_{a}$ : Heat generated by aerodynamic drag, J

$\Phi_{c}$ : Convection heat, J

$A^{\prime}$ : $\quad$ External surface of the brake drum, $\mathrm{m}^{2}$

$h_{c}$ : Surface heat transfer coefficient

a: $\quad$ Empirical formula coefficient, $\mathrm{W} /\left(\mathrm{m} \cdot{ }^{\circ} \mathrm{C}\right)$

$t_{w}$ : Temperature of the external surface of the brake drum, ${ }^{\circ} \mathrm{C}$

$t_{f}$ : Temperature of the fluid on the external surface of the brake drum, ${ }^{\circ} \mathrm{C}$

$\Phi_{r}: \quad$ Radiant heat, J

$\varepsilon: \quad$ Emissivity of the brake drum

$C_{0}$ : Radiance of the black body, $\mathrm{W} /\left(\mathrm{m}^{2} \cdot \mathrm{K}^{4}\right)$

$T_{1}$ : Thermodynamic temperature of the black body, $\mathrm{K}$

$T_{2}$ : Ambient temperature, $\mathrm{K}$

$Q_{d}$ : Heat exchanged between the heat conduction object and fluid, J $t: \quad$ Travel time of the truck downgrade, $\mathrm{s}$

$j$ : Subinterval for integral calculation,

$j=(1 s, 2 s, 3 s, \ldots)$

$t_{w j}: \quad$ Brake temperature corresponding to the $j^{\text {th }}$ subinterval

$Q_{1}{ }^{\prime}$ : $\quad$ First portion of the heat that increases the brake drum temperature, J

$Q_{F}: \quad$ Heat distributed to the front brakes, J

$\beta$ : $\quad$ Braking force distribution coefficient

$n_{1}$ : Number of front axles

$Q_{R}$ : Heat distributed to the rear brakes, J

$n_{2}$ : Number of rear axles

$Q_{1}$ : Heat equally distributed to each brake during the speed control stage, J

$n$ : $\quad$ Number of truck axles

$T_{f 1}$ : Increase in the brake drum temperature in the speed control stage, ${ }^{\circ} \mathrm{C}$

$T_{0}$ : $\quad$ Initial temperature of the brake drum, ${ }^{\circ} \mathrm{C}$

$m^{\prime}$ : $\quad$ Single brake drum weight, $\mathrm{kg}$

$C: \quad$ Heat capacity of the brakes, $\mathrm{J} /\left(\mathrm{kg} \cdot{ }^{\circ} \mathrm{C}\right)$

$Q_{2}$ : Second portion of the heat that increases the brake drum temperature, J

$T_{f 2}$ : Increase in the brake drum temperature in the emergency braking stage, ${ }^{\circ} \mathrm{C}$

$T_{f}$ : $\quad$ Predicted temperature of the brake drum, ${ }^{\circ} \mathrm{C}$

$\Delta h: \quad$ Height difference, $\mathrm{m}$

temp $p_{1}$ : Brake drum temperature, after the speed control stage, ${ }^{\circ} \mathrm{C}$

temp $p_{2}$ : Brake drum temperature, after the emergency braking stage, ${ }^{\circ} \mathrm{C}$.

\section{Data Availability}

The data used to support the findings of this study are available from the corresponding author upon request.

\section{Conflicts of Interest}

The authors declare that there are no conflicts of interest regarding the publication of this paper.

\section{Acknowledgments}

This research was partly supported by the National Key Research and Development Program of China (no. 2016YFC0802208).

\section{References}

[1] National Highway Traffic Safety Administration, "2016 Fatal motor vehicle crashes: overview," Traffic Safety Facts Research Note, vol. 2017, p. 10, 2017.

[2] J. Hedlund and D. Blower, Large truck crash causation study (LTCCS) analysis series: Using LTCCS data for statistical analyses of crash risk, 2006.

[3] A. Lill Richard, Review of BMCS analysis and summary of accident investigations, 1973-1976, With respect to downgrade 
runaway type accidents, Inc., Memorandum, American Trucking Associations, 1977.

[4] A. W. Johnson, J. R. Dimarco, and R. W. Allen, "Development and evaluation of a prototype grade severity rating System," Design, 1982.

[5] D. Middleton and K. Fitzpatrick, "Truck accident countermeasures for urban freeways," ITE Journal (Institute of Transportation Engineers), vol. 66, no. 11, pp. 44-51, 1996.

[6] P. G. Hykes, "Truck downgrade control prediction procedure," SAE, p. 630A, 1963.

[7] R. A. Lill, Development of grade severity rating system, American Trucking Associations, 1975.

[8] B. L. Bowman, "Grade severity rating system (GSRS): User manual," Downgrades, 1989.

[9] T. T. Myers, I. L. Ashkenas, and W. A. Johnson, Feasibility of a grade severity rating system, 1980.

[10] F. R. Hanscom, "Field test of the grade severity rating system (GSRS): Final report," Highway Grades, 1985.

[11] K. Ksaibati and D. Ph, Updating and implementing the grade severity rating system (GSRS) for Wyoming Mountain Passes, 2016.

[12] University of Michigan Transportation Research Institute, Engineering Research Division, Simplified models of truck braking and handling, 1990.

[13] W. Yuan, Temperature rise calculation model of drum brake and its application, Changan University, China, 2003.

[14] Y. S. Guo, W. Yuan, and R. Fu, "Solving the convective heat transfer coefficient of automobile drum brake by experimental method," Journal of Chang'an University (Natural Science Edition), vol. 26, no. 7, pp. 92-107, 2006.

[15] H. Yang, Q. Hu, and J. Xu, "Safety design and evaluation method of expressway downgrade sections," Journal of Transportation Engineering, vol. 10, no. 3, pp. 10-16, 2010.

[16] A. Floquet and M. C. Floquet, "Nonaxisymmetric effects for three-dimensiooal analysis of a brake," Journal of Tribology, vol. 116, no. 3, pp. 401-407, 1994.

[17] C. H. Gao and X. Z. Lin, "Transient temperature field analysis of a brake in a non-axisymmetric three-dimensional model," Journal of Materials Processing Technology, vol. 129, no. 1-3, pp. 513-517, 2002.

[18] Y. S. Guo, R. Fu, and P. F. Yang, "Numerical simulation and calculation for transient thermal field of drum brake," Journal of Chang'an University, vol. 26, no. 3, pp. 87-90, 2006.

[19] X. Shi, J. Ni, and Y. Zheng, "3-D Numerical simulation and computation for transient temperature field of drum brake," in Proceedings of the 2011 International Conference on Electri Information and Control Engineering, pp. 4701-4704, IEEE, 2011.

[20] X. Ma, F. L. Ji, and Q. L. Yang, "Finite element analysis of direct thermal-structure coupling of drum brakes," Mechanical Transmission, vol. 38, no. 1, pp. 129-133, 2014.

[21] D. K. Witheford, Truck Escape Ramps, 1992. 


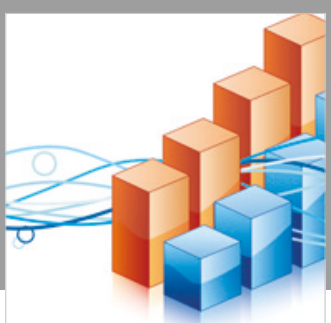

Advances in

Operations Research

\section{-n-m}
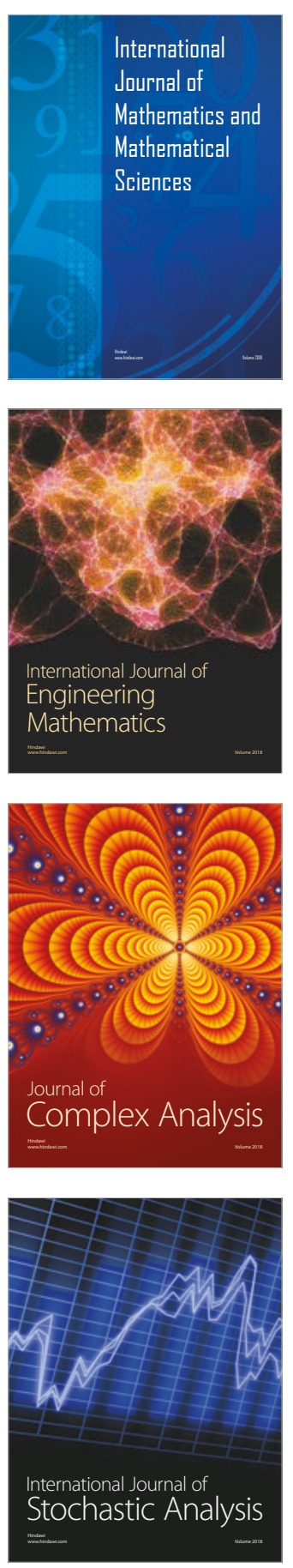
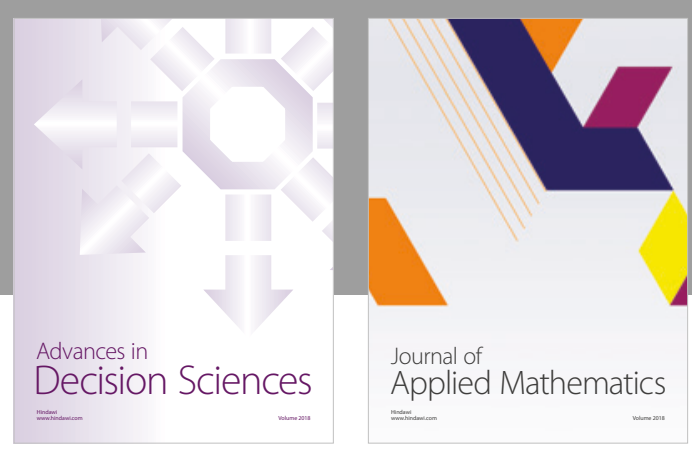

Journal of

Applied Mathematics
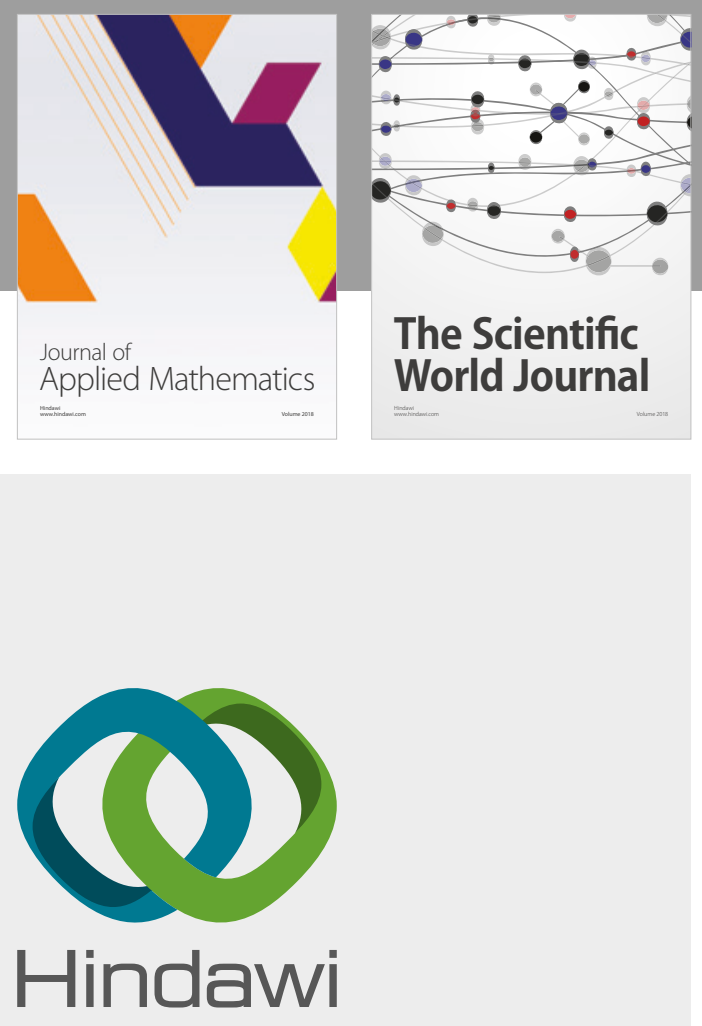

Submit your manuscripts at

www.hindawi.com

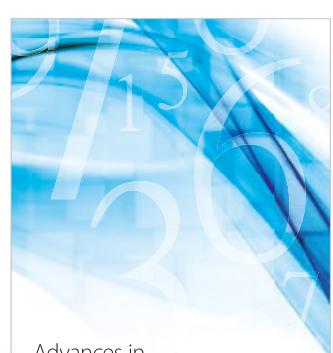

Advances in
Numerical Analysis
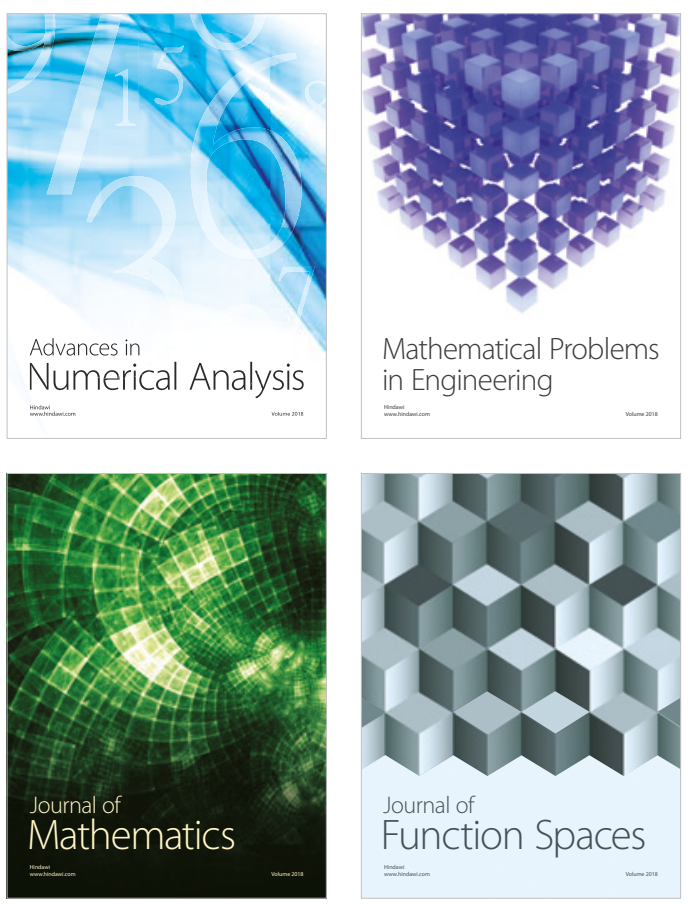

Mathematical Problems in Engineering

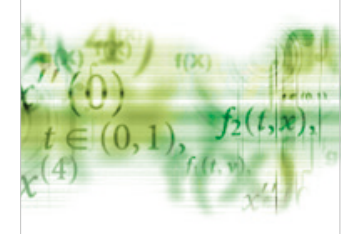

International Journal of

Differential Equations

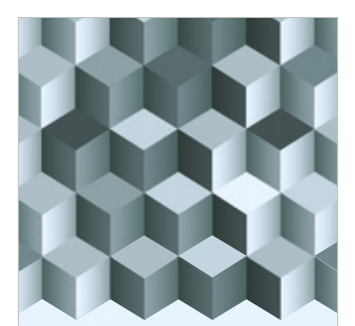

Journal of

Function Spaces

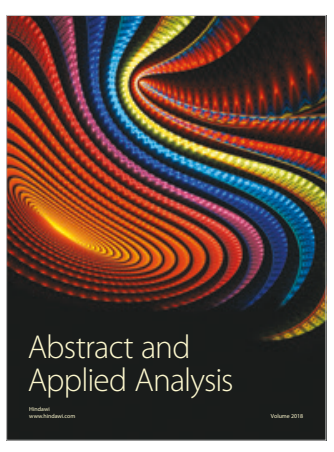

The Scientific

World Journal

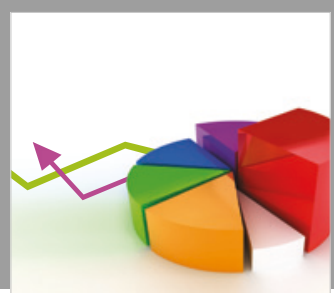

Journal of

Probability and Statistics
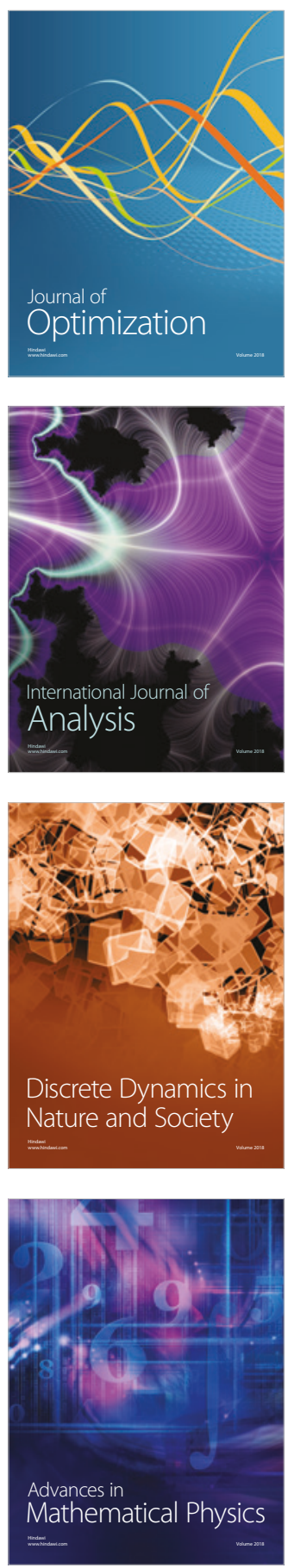